\title{
DEPTH OF CRACKING BENEATH IMPACT CRATERS: NEW CONSTRAINT FOR IMPACT VELOCITY
}

\author{
Thomas J. Ahrens*, Kaiwen Xia*, and Demirkan Coker $\dagger$ \\ *Seismological Laboratory 252-21, California Institute of Technology, Pasadena, CA 91125 \\ † Guggenheim Aeronautics Laboratory 105-50, California Institute of Technology, Pasadena, CA 91125
}

\begin{abstract}
Both small-scale impact craters in the laboratory and less than $5 \mathrm{~km}$ in diameter bowlshaped craters on the Earth are strength (of rock) controlled. In the strength regime, crater volumes are nearly proportional to impactor kinetic energy. The depth of the cracked rock zone beneath such craters depends on both impactor energy and velocity. Thus determination of the maximum zone of cracking constrains impact velocity. We show this dependency for small-scale laboratory craters where the cracked zone is delineated via ultrasonic methods. The $1 \mathrm{~km}$-deep cracked zone beneath Meteor Crater is found to be consistent with the crater scaling of Schmidt (1) and previous shock attenuation calculations.
\end{abstract}

\section{INTRODUCTION}

Impact-induced fractures in rock have long been recognized beneath terrestrial impact craters. Simmons et al. (2) pointed out that the multiply impacted near-surface rocks on the Moon were fractured to depths of tens of kilometers and the fracture density controls the near-surface seismic velocity structure. Dvorak and Phillips (3) discovered cracks beneath young fresh craters that were unfilled on the Moon, or filled with air or water on the Earth gave rise to significant (negative) gravity anomalies. Ahrens and Rubin (4) demonstrated that the seismic velocity of rocks beneath small laboratory, strength-limited, craters increased with depth. This results from the near-surface zone of cracking beneath craters. The intensity of cracking decreases with increasing depth reflecting the decreasing dynamic tensile stresses with depth in the rock. The volume of strengthcontrolled impact craters has been demonstrated to be nearly proportional to impactor energy for soft and hard rocks (5).
In the present report we show that the depth of cracking is related to the spatial attenuation rate of the impact-induced shock wave. This is, in turn, related to the impact velocity. Thus given the dimensions of the crater, and the depth of rock cracking, in principle, these data can be combined to provide constraints on impactor velocity. Since on the Earth, the asteroidal impact velocity range is from $\sim 18$ to $25 \mathrm{~km} / \mathrm{sec}$ and cometary impactors encounter the Earth from 30 to $75 \mathrm{~km} / \mathrm{sec}$, it may now be possible to differentiate between the different craters produced by these objects. Traces of siderophilic elements from the impactor sometimes are preserved in the impact-induced melt. For some craters, samples of the impactor are discovered within the ejecta blanket. Fragments of Meteor Crater's impactor (Canyon Diablo meteorite) were strewn around the crater rim, when it was discovered in $\sim 1880$.

On a larger scale, on the Earth, bowl-shaped impact craters with diameters up to several kilometers appear to be strength controlled. Beneath these craters the maximum depth of 
crack damage is approximately proportional to crater diameter. For example, the $1.2 \mathrm{~km}$ diameter Meteor Crater in Arizona displays a zone $\sim 1 \mathrm{~km}$ deep of severely cracked rock. This feature was outlined by Ackermann et al. (6) using seismic refraction methods. The maximum depth of damage for Meteor Crater and other terrestrial impact structures (Table 1) versus crater diameter are plotted in Fig. 1. At diameters greater than $\sim 10 \mathrm{~km}$, the initial bowlshape of impact craters are usually collapsed and the crater floors are flattened. Larger diameter craters also display central peaks and concentric rings as a result of the gravitation stresses that dominate the final crater shapes.

TABLE 1. Depth of Damage $\left(L_{D}\right)$ for Terrestrial Impact Craters

\begin{tabular}{lcc} 
Crater Name & $\begin{array}{c}\text { Crater } \\
\text { Diameter } \\
(\mathbf{k m})\end{array}$ & $\begin{array}{c}\text { Maximum } \\
\text { Depth of } \\
\text { Damage } \\
\mathbf{L}_{\mathrm{D}}(\mathbf{k m})\end{array}$ \\
\hline Meteor, USA & 1.2 & 1.0 \\
Brent, CAN & 3.0 & 0.3 \\
West Hawk Lake, & 3.7 & 1.25 \\
CAN & 4.0 & 0.9 \\
Gow Lake, CAN & 5.0 & 2.0 \\
Upheaval Dome, USA & 5.5 & 0.5 \\
Soderfjarden, FI & 2.0 & 5.0 \\
Gosses Bluff, AU & 23.0 & 6.0 \\
Ries, DE & 46.0 & 8.0 \\
Charlevoix, CAN & 45.0 & 9.0 \\
Manicouagan, CAN & 65.0 \\
Chicxulub, MEX & 165.0 & 11.0 \\
Vredefort, SA & 300.0 & 14.0 \\
\hline
\end{tabular}

Shock-induced cracking beneath small-scale craters excavated in rock samples appears to be controlled by the same physics as the cracking observed beneath strength-controlled natural craters up to several kilometers in diameter on the Earth. We studied the extent of impactinduced cracking beneath craters so as to employ these data to specify the impact conditions required to induce a given crater. We are especially interested in applying the seismic data on terrestrial craters. In the future we expect additional seismic data for crater structures on the Earth and on other planets to become available.

Here we summarize two methods used to measure the shock damage beneath laboratory induced craters in rock targets. We relate the resulting seismic velocity profiles (reflecting shock damage versus depth) to a simple model of shock attenuation and propose a model to relate shock attenuation rate and impactor velocity to the intensity and distribution of shock damage.

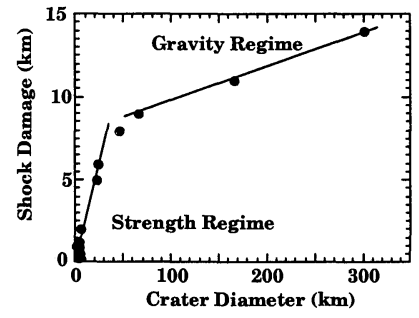

FIGURE 1. Depth of shock damage, versus, crater diameter for terrestrial impact craters (Table 1). Strength regime corresponds to bowl-shaped strength-controlled simple craters. Gravity regime corresponds to complex (central peaks and multi-ringed) craters that have suffered major failure from gravitational stresses.

\section{EXPERIMENTS}

San Marcos gabbro (7) targets $(\sim 15 \mathrm{~cm}$ on side) were impacted with $0.8 \mathrm{~g}$ aluminum projectiles at velocities of 0.8 to $1.2 \mathrm{~km} / \mathrm{sec}$. The resulting impact-induced bowl-shaped craters, $\sim 5 \mathrm{~cm}^{3}$, in volume displayed zones of cracked rock beneath the craters (Fig. 2). Budiansky and O'Connell (8) first showed that dry circular cracks in solids (rocks) cause the bulk and shear moduli, $\overline{\mathrm{K}}$ and $\overline{\mathrm{G}}$, to be decreased relative to that of the uncracked rock moduli ( $\mathrm{K}$ and $\mathrm{G}$ ). Hence, the elastic wave velocities are strongly reduced by cracks in rock. Cracking is defined in terms of the damage parameter $\varepsilon=\mathrm{N}\left\langle\mathrm{a}^{3}\right\rangle$, where $\mathrm{N}$ is the number of (circular) cracks per unit volume of average radius, a. Thus

$$
\overline{\mathrm{K}}=\mathrm{K} /\left[1+\frac{16}{9} \frac{(1-\overline{\mathrm{v}})^{2}}{(1-2 \bar{v})} \varepsilon\right]
$$

and

$$
\overline{\mathrm{G}}=\mathrm{G} \cdot\left[1-\left(\frac{32}{45}\right) \cdot \frac{(1-\bar{v})(5-\bar{v})}{(2-\bar{v})} \varepsilon\right]
$$

where $v$ and $\bar{v}$ are the uncracked and cracked Poisson's ratio and

$$
\bar{v}=v\left[1-\left(\frac{16}{9}\right) \varepsilon\right]
$$


We employed two methods to measure the distribution of compressional wave velocity $\mathrm{C}_{\mathrm{p}}=$ $\sqrt{\left(\overline{\mathrm{K}}+\frac{4}{3} \overline{\mathrm{G}}\right) / \rho}$, where $\rho$ is the density of the

rock. These are the tomographic and dicing methods outlined below.

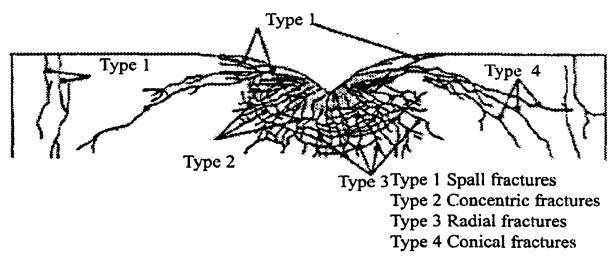

FIGURE 2. Cross-section of laboratory impact crater in San Marcos gabbro, demonstrating the four types of crack failure discussed by Ahrens and Rubin (4) (after Polanskey and Ahrens (9)).

To map the region of velocity deficit below the crater, we conducted a small-scale seismic survey. We measured the compressional wave velocity by deploying a pulsed 480 erg $(\sim 0.2$ $\mathrm{MHz}$ ) ultrasonic source (10) at three stations on the impact surface to the left of the crater in Fig. 3 . The pulsed excitation signal was recorded at the 24 stations (Fig. 3) on the left side and bottom of the target block. We detected compressional waves that propagated along the assumed 72 straight line paths also is shown in Fig. 3. This data set (measured to a precision of $\pm 0.05 \mu \mathrm{s}$ ) was inverted to obtain a 2 -dimensional compressional wave velocity map over the $15 \mathrm{x}$ $15 \mathrm{~cm}$ biaxially symmetric (about the axis of impact) grid of Fig. 3, using the least squares damping method of Menke (11). The velocity obtained for the heavily damaged regions centered at the 1,2 , and $3 \mathrm{~cm}$ cells, below the crater (for one sample) are plotted in Fig. 4.

Subsequently, for one of the experiments, the impacted rock sample was sawn open and $\sim 1 \mathrm{~cm}$ cubes of rock were cut from a series of 6 positions directly beneath the axis of the crater. Compressional-wave travel times and hence propagation velocities were measured $( \pm 0.1$ $\mathrm{km} / \mathrm{s}$ ) and these are also plotted in Fig. 4.

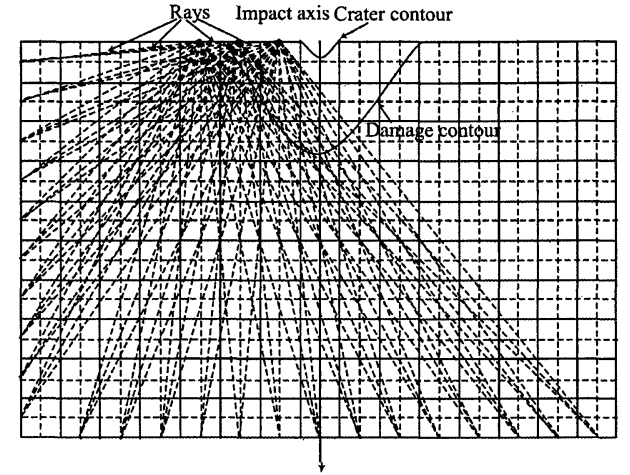

FIGURE 3. Tomographic ray diagram. Three stations on upper surface site of pulsed excitation of compressional waves. Wave detection stations (24) along left side and bottom of target block interrogated target along diagonal dashed lines (rays). One-centimeter inversion grid, crater and damage contours are also shown.

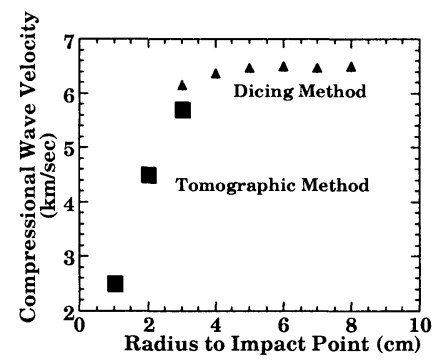

FIGURE 4. Compressional wave velocity below strengthcontrolled impact craters in rock. Tomographic inversion results are seen to delineate heavily damaged region beneath crater whereas dicing method provides complimentary data for deeper less damaged rock.

\section{APPLICATION TO METEOR CRATER}

The decay of an impact-induced shock wave was described by Ahrens and O'Keefe (12) using the relation

$$
\mathrm{P}(\mathrm{r})=\mathrm{P}_{0}\left(\mathrm{r} / \mathrm{r}_{0}\right)^{-\mathrm{n}}
$$

where $r_{0}$ is the radius of a spherical impactor ( 3.5 $\mathrm{mm}$, here) and $\mathrm{P}_{0}$ is the contact impact pressure calculated from the shock-wave impedancematch solution. We define $P_{c}$ as the critical tensile stress required for cracking and assume that when the compressional pulse decays such that $\left|P_{c}\right|=P(r)$, the depth is the maximum depth of cracking. This occurs at $r=L_{D}$, for the deepest extending cracks (radial) (see Fig. 2). 
Our experiments yielded maximum depths of cracking over the range, 3.5 to $4.5 \mathrm{~cm}$, from impacts at 0.8 to $1.0 \mathrm{~km} / \mathrm{sec}$. Upon fitting to Equation 4, we found $n=1.6$ and $P_{c}=0.17 \mathrm{GPa}$.

Using the value of $L_{D}$ from Table 1 for Meteor Crater, we assume $P_{c}$ (for the Coconino sandstone unit) ranges from 0.10 to $0.15 \mathrm{GPa}$. Fixing the impact velocity value at $\sim 20 \mathrm{~km} / \mathrm{s}$, (we know Canyon Diablo meteorite was initially a metallic asteroid), the value of the attenuation index concordant with Shoemaker's (13) value of the initial radius of the impactor of $11 \mathrm{~m}$ yields attenuation indices in the 1.75 to 1.85 range (Fig. 5). A more recent estimate of $r_{0}=31$ $\mathrm{m}$ based on using an improved theory of crater scaling yields $\mathrm{n}=2.4$ to 2.5 The latter are in good accordance with Ahrens and O'Keefe's (12) results for impact of an iron meteorite on a silicate half-space between 15 and $45 \mathrm{~km} / \mathrm{s}$.

\section{CONCLUSIONS}

1. In the strength controlled cratering regime (crater diameter, $<5 \mathrm{~km}$, which also extends also to laboratory samples) the maximum depth of shock-induced cracking corresponds closely to the radius at which the amplitude of the decaying shock wave is approximately equal to the rock dynamic tensile strength.

2. Since the shock attenuation parameter depends on relative shock impedance of impactor and target rock, as well as impactor velocity, if the impactor type can be constrained from either recovery of impactor fragments or the geochemical signature in the impact melt, the depth of crack damage (taken with impactor energy inferred from crater volume) constrains impactor velocity.

3. In the case of Meteor Crater, where the maximum depth of crack damage is $1 \mathrm{~km}$, using the crater scaling of Schmidt (1) to infer a $31 \mathrm{~m}$ radius iron-nickel impactor predicts a shock attenuation index of 2.4 to 2.5 for tensile strengths of 1.0 to $1.5 \mathrm{kbar}$. This agrees with calculations of the attenuation indices of 2.4 and 2.6 obtained for iron impacting silicate at 15 and 45 $\mathrm{km} / \mathrm{sec}$, respectively.

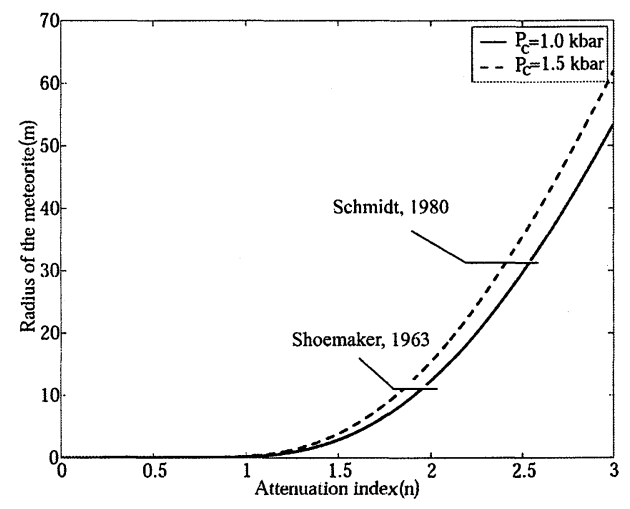

FIGURE 5. Inferred $20 \mathrm{~km} / \mathrm{sec}$ iron impactor radius versus shock attenuation index (Eq. 4). Peak shock pressure at depth of maximum extent of damage for Meteor Crater (assumed solid, $1.0 \mathrm{kbar}$, and dashed, $1.5 \mathrm{kbar}$ strength). Impactor radius of 11 and $31 \mathrm{~m}$, from scaling of Shoemaker (13) and Schmidt (1) indicated.

\section{ACKNOWLEDGMENTS}

Research supported by NASA. Contribution number 8816, Division of Geological and Planetary Sciences.

\section{REFERENCES}

1. Schmidt, R.M., Proc. Lunar Planet. Sci. Conf., 11th, 2099-2128 (1980).

2. Simmons, G., Todd, T. and Wang, H., Science, 182, 158-161'(1973).

3. Dvorak, J. and Phillips, R.J., Geophys. Res. Lett., 4, 380-382 (1977).

4. Ahrens, T.J. and Rubin, A.M., J. Geophys. Res., 98, 1185-1203 (1993)

5. Holsapple, K.A., Ann. Rev. Earth Planet. Sci., 21, 333-373 (1993).

6. Ackermann, H.D., Godson, R.H. and Watkins, J.S., J. Geophys. Res., 80, 765-775 (1975).

7. Lange, M.A., Ahrens, T.J. and Boslough, M.B., Icarus, 58, 383-395 (1984).

8. Budiansky, B. and O'Connell, R.J., Int. Journal Solids and Structures, 12, 81-97 (1976).

9. Polanskey, C. and Ahrens, T.J., Icarus, 87, 140155 (1990).

10. Xia, K. and Ahrens, T.J., Geophys. Res. Lett., accepted for publication (2001).

11. Menke, W., Geophysical Data Analysis: Discrete Inverse Theory, San Diego: Academic Press, 1989.

12. Ahrens, T.J. and O'Keefe, J.D., in Impact and Explosion Cratering, Roddy, D. J., R. O. Pepin and R. B. Merrill (eds.), Pergamon, New York, 1977, pp. 639-656

13. Shoemaker, E.M., in The Solar System: Moon Meteorites, and Comets, Middlehurst, B. M. and G. P. Kuiper (eds.), University of Chicago Press, Chicago, IL, 1963, pp. 301-336. 